Portland State University

PDXScholar

\title{
Communication Methods in Healthcare for Latinos with Limited English Proficiency: Physician Language Concordance and Children as Translators
}

Katie Castellanos

Portland State University

Follow this and additional works at: https://pdxscholar.library.pdx.edu/honorstheses Let us know how access to this document benefits you.

\section{Recommended Citation}

Castellanos, Katie, "Communication Methods in Healthcare for Latinos with Limited English Proficiency: Physician Language Concordance and Children as Translators" (2016). University Honors Theses. Paper 235.

https://doi.org/10.15760/honors.252

This Thesis is brought to you for free and open access. It has been accepted for inclusion in University Honors Theses by an authorized administrator of PDXScholar. Please contact us if we can make this document more accessible: pdxscholar@pdx.edu. 
COMMUNICATION METHODS IN HEALTHCARE FOR LATINOS WITH LIMITED ENGLISH PROFICIENCY: PHYSICIAN LANGUAGE CONCORDANCE AND CHILDREN AS TRANSLATORS

\author{
By \\ Katie Castellanos \\ An undergraduate honors thesis submitted in partial fulfillment of the \\ requirements for the degree of \\ Bachelors of Science \\ In \\ University Honors \\ And \\ Health Studies: Health Science
}

Thesis Advisor

Cara L. Eckhardt

Portland State University 


\section{TABLE OF CONTENTS}

$\begin{array}{ll}\text { Abstract } & 3\end{array}$

$\begin{array}{ll}\text { Introduction } & 3\end{array}$

$\begin{array}{lr}\text { Methods } & 6\end{array}$

$\begin{array}{lr}\text { Findings } & 6\end{array}$

$\begin{array}{ll}\text { Conclusion } & 14\end{array}$

$\begin{array}{lr}\text { Reference } & 18\end{array}$ 


\begin{abstract}
The goal of this thesis was to examine the primary methods of communication that Latinos with limited English proficiency (LEP) use when professional translators are not available. Latinos constitute $17 \%$ of the United States population, $64 \%$ of which have limited English proficiency. A literature review was conducted to identify research done in regards to children as translators and physician language concordance. Two themes of communication for Latinos with LEP in the absence of professional translators emerged from the literature review: the use of children as translators, and reliance on physician language concordance. Providers should take caution when working with these children in order to avoid misdiagnosis for their parents, understanding the stress and possibility for miscommunication when children translate. Physician language concordance was shown to lead to greater patient satisfaction and improved health outcomes and should be the gold standard in LEP patient care. These two methods of communication are some of the ways patients with limited English proficiency interact with physicians when seeking healthcare.
\end{abstract}

\title{
INTRODUCTION
}

When Latinos with limited English proficiency access healthcare, along with social and political barriers, they are faced with language barriers in physician communication. In the US, Spanish speakers have the highest rates of limited English proficiency and a lower national 
average of being fluent in English (US Census, 2014). As of 2014, the Latino population constituted 17\% of the United States population at 55 million individuals (US Census, 2014).

Limited English Proficiency (LEP) is an issue that has not decreased over time. According to the U.S. Census Bureau, the percentage of people who spoke Spanish but did not speak English stayed consistent from 2005 to 2011 (Ryan, 2013). Within the US, Latino Spanish speakers make up about $60 \%$ of those who speak a language other than English and of these Spanish speakers, 64\% have LEP (Perez-Escamilla, 2010).

Latinos with LEP experience health disparities including obesity and Type 2 Diabetes. The Latino population with LEP, as compared to Latinos with English proficiency, have poorer health outcomes even when adjusted for age, gender, and education (Perez-Escamilla, 2010). Although not further broken down by English proficiency, research shows that Latinos in general have a greater risk of Type 2 Diabetes than non-Latinos with the current prevalence of $17 \%$ (Alexandria, 2014). Obesity also disproportionally effects Latinos with almost 1 in 4 Latino children being overweight (CDC, 2015). In addition, 77\% of adult Latinos suffer from obesity (Ogden et al., 2012). Given that $64 \%$ of Spanish speakers have LEP, it can be assumed that these disparities will be more pronounced within this subpopulation of Latinos.

Language barriers pose a significant healthcare issue with the rising Latino population in the US and the increasing access to healthcare. As of $2013,75.7 \%$ of the Latino population had insurance (US Census, 2014). This number is expected to increase with the implementation of the Affordable Care Act, as millions of eligible families gain health insurance. In addition, the US now has 41 million native Spanish speakers, and another 11.6 million bilingual individuals, mainly the children of Spanish-speaking immigrants (Burgen, 2015). With the US Census 
projecting 138 million Spanish-speakers by 2050, the United States will become the largest Spanish-speaking country in the world (Burgen, 2015).

When a patient with LEP seeks medical attention they are often presented with one of the three modes of communication: physician language concordance, professional translation or family member translation, often their child. Paid translators are considered the gold standard for addressing LEP in patient care, and there is a well-developed debate about their pros and cons in the literature. However, paid translators are often unavailable and underqualified and the other two modes of communication are employed. Furthermore, compared to the literature on professisonal translators, little has been written about the strengths and limitations of physician language concordance and children as translators. The Institute of Medicine lists Patient Centeredness as one of six key methods to improve the quality of care in the US Healthcare System, (Fernandez, 2004). Patient centeredness can be achieved through concordance, described as "shared identities between patients and providers" (Powe et al., 2004). This paper will be examining how specifically language concordance plays a role in the patient care of Latinos with limited English proficiency. In the context of LEP, physician language concordance, may allow for the patient-provider relationship to develop and for communication to move more freely in a common spoken language.

With the growing population and increased access to healthcare post Affordable Care Act, addressing language barriers will be crucial in the promotion of greater health outcomes. It is my hope that this paper be of benefit for public health interventionists working within diabetes control and for physicians working in predominantly Spanish-speaking populations. This paper will specifically address physician language concordance and children as translators. 


\section{METHODS}

A literature review was conducted to evaluate physician language concordance and children as translators within Latinos with LEP. "Healthcare, "Latinos", "Limited English Proficiency" was searched as a single term, combined with "children as translators," as well as with "physician language concordance" within two search engines: Academic Search Premier and Google Scholar. All articles, peer reviewed and journalistic, from the year 2000 and onward that discussed children as translators and physician language concordance in the Latino population within the context of the US healthcare system were included. Articles with non-US healthcare research were excluded. This search produced seven articles relating to children as translators, and eight articles relating to physician language concordance.

\section{FINDINGS}

\section{Children as Translators}

A review of the seven articles focusing on children as translators produced four overarching themes: parental dependence, child stress, age appropriateness, children's lack of maturity to translate, and poor health outcomes resulting from miscommunication and parental withholding. The literature shows that bilingual English and Spanish children may be qualified to interpret in settings without professional translators. Van Tran from Harvard University says that "Spanish at home and in school has no effect on English acquisition, but significantly promotes Spanish retention" (Tran, 2010, Arriagada, 2005). Children's language and communication skills can make them valuable assets in emergency medicine situations when professional translators 
are not available within time and resource constraints, however the ethical implications of children translating can far outweigh the benefits.

\section{Parental Dependence}

Parents with LEP are often dependent on their children to interpret and help navigate in medical settings when alternative translators are not available (Orellana et al, 2003, Jauregui, 2006). One of the seven articles, a journalistic report from Antony Jauregui at National Public Radio (NPR) featured a seventeen-year-old girl who has been acting as a translator for her mother since the age of twelve. At age 17, the young woman's mother was pregnant and attended a women's health clinic where the providers did not speak Spanish. The patient was thankful to have her daughter translate for her as this allowed her to ask more in depth questions to the provider and gain clarification when needed. In a 2003 study, a child reported that reported how dependent her mother was stating, "my mother has never gone anywhere alone" (Orellana et al., 2003). Parental dependence can be greater in areas where all encounters have to be in English. Having family members accompany patients with LEP also assists patients when trying to navigate the overwhelming healthcare system within the US. Although this may help parents, this dependence can cause stress on a child to be responsible for tasks otherwise not age appropriate.

\section{Child Stress}

Despite bilingualism ability, translating for parents can cause significant stress on a child. NPR's Antony Jauregui reflected on translating for his parents as a child, "I'll never forget this one time when someone in my family was in the hospital. All of a sudden, my mom was like, 
you have to translate. But what the doctors said confused me. And all my family kept saying was, Are you sure? Did they really say that?" (2006) In a qualitative study performed in Chicago and Los Angeles, Orellana et al. found that children of Latino immigrants with LEP often translate in many capacities from medical billing to canceling and forming doctor's appointments (2003). Of the 236 Spanish-speaking children interviewed, $40 \%$ of the children had translated in a doctor's office and 30\% had translated at the dentist's office. Many of the children shared stories of stress from translating for their parents. Twelve-year-old named Amanda recounted the time of translating in emergency room with her mother and brother because her brother had cut himself with knife, "I was so so nervous. I could almost not talk, but I did it" (Orellana et al., 2003).

\section{Ethics of Children Translating}

The appropriateness of having a child in certain medical settings was often discussed (Cohn, 2014, Foden-Vencil, 2014, Jauregui, 2006, Orellana et al., 2003). Primary care health clinics tend to have less access to translators in comparison to emergency departments and inpatient units, thus children have to interpret more often in these settings. Foden-Vencil argue that it can be inappropriate to have a child translate during a mother's gynecological visit and potentially traumatizing to have a child convey a cancer diagnosis (2014). Dr. Flores shared a similar example of a boy interpreting for a mother having gynecological issues stating that it's never appropriate to depend upon a child to interpret (Cohn, 2014). A young girl recounted taking her mother to the doctor and having to interpret and make medical decisions beyond her responsibility:

I used to have to translate for my mom at the doctor's office so much that it came to the 
point where the doctor would only talk to me. He wouldn't even look at my mom. Instead he would ask me for updates and symptoms. Afterwards he would give me his recommendations and had me choose what the best options would be for my mom. Often I had to interrupt him to explain what had been going on with my mom and to ask her what she thought, but I must admit that sometimes I made choices for her without asking her first (Orellana et al., 2003).

\section{Miscommunications}

Misunderstandings by children with lack of medial knowledge has lead to misdiagnosis. Assemblyman Leland Yee for California stated, "Kids don't have the vocabulary, nor the content knowledge about what they're translating" (Jauregui, 2006). Dr. Flores of the California Endowment also stated that children lack the maturity to "understand the importance and the seriousness of medical discussions" and this can lead to misunderstandings with serious health problems (Cohn, 2014). In 2005 and 2013 the state of California sought to ban children under 15 years of age for interpreting for parents in all medical situations due to the implications of misdiagnosis. With the Affordable Care Act now insuring more Spanish-speaking families, the use of child translators has been exacerbated (Cohn, 2014). Children could lack the vocabulary needed to effectively communicate with a physician. Eleven-year-old Jasmine reported misunderstandings when translating in an interview to Orellana et al. (2003):

When I was about 8-9 years old we went to the doctor because my baby brother was 1 month or so. He had to go for a check up and a doctor told (asked) my mom if she was going to give my baby brother milk from he(r) breast, but I did not know what breast meant. So I told the doctor if she 
could explain what breast meant. She was nice and kind and said yes of course. She touched her breast and (I) told my mom what the doctor was saying. As far as I can remember this was the scariest translating thing I (had) ever done. I did not translate things that much this week but I did work (a) long time ago translating stuff. Well, I felt so nervous to translate for the doctor because I thought I would not be able to understand the big words doctors use.

\section{Misdiagnoses}

Miscommunications can lead to long term health outcomes and malpractice claims. In 2010 Quan reviewed 35 cases of malpractice claims involving language services and the LEP population and found that 32 cases involved failure to provide competent translators, with 12 of the cases involving children as translators. In one case, a Spanish-speaking patient suffered irreversible brain damage because the physicians were unable to get a past medical history before the patient suffered cardiac arrest. During this incident the patient's daughter was translating for the physicians and her mother via the phone (Quan, 2010). Although children as translators can be a quick solution in emergency medical situations, it can lead to long-term health and financial outcomes that outweigh the cost of professional translators for a hospital.

\section{Parental Withholding}

Additionally, parents may withhold valuable medical history when their child is translating. There is also the fear that parents may withhold information with the intent of protecting their child however this would compromise the efficacy of the medical appointment 
(Cohn, 2014). For example, women suffering domestic violence may be unable to disclose to a provider or report accurate information when their child is translating for them.

\section{Physician Language Concordance}

From the search the following themes arose: patient satisfaction, improved communication, and improved health outcomes. Physician language concordance has been known to improve health outcomes however the literature shows that health outcomes are also improved due to the greater patient-physician communication, and patient satisfaction.

\section{Greater Patient Satisfaction}

Physician language concordance improved patient trust. Language concordance leads to a stronger patient-physician bond which can stimulate discussion and greater patient self-care upon discharge. Wilson et al. conducted phone surveys in the patients preferred language regarding medical comprehension and the presence of a language concordant physician (2005). They found that a stronger patient-physician trust is formed when language-concordant interactions are made in a clinical setting. It can be difficult enough for patients to disclose health information to a provider, but the presence of a translator can increase the difficulty within vulnerable populations. Physician language concordance improved patient-provider rapport as compared to physicians using a translator. Street et al. conducted a cross-sectional study with 214 patients and 29 primary care doctors and found that the physician-patient rapport is strengthened when patients feel and have similar beliefs, values, and a common language (Street et al., 2008). These perceived similarities are associated with higher patient ratings for trust, satisfaction and intention to adhere with medical guidance. Bauer et al. interviewed 28 abused Latino and Asian 
immigrant women in San Francisco and identified social, political and cultural barriers when accessing healthcare (2000). A Latina explained her difficulty communicating in an Englishcentered healthcare system, "Language is a very important factor. It's very important, not because you don't trust what they don't translate, but because when a third person is used, you lose that contact which is very much a part of us, and it puts more distance between the doctor and the patient" (Bauer et al, 2000). The presence of a translator can create distance between the patient and the provider and interfere with the trust and rapport.

Patient satisfaction was greater for patients with physician language concordance. Fernandez and colleagues studied the physician-patient relationship to determine how physician's self-rated Spanish-language ability and cultural competency related to Spanishspeaking patients reports of interactions and communication. Research showed that Spanishspeaking patients were less satisfied with their care when their provider was a non-Spanishspeaking physician (Fernandez et al., 2004). The subjects in that study were more likely to report better interpersonal processes of care when their physician had a higher self-rated Spanishspeaking ability and cultural competency (Fernandez, 2004). Latino physician ethnicity was also strongly correlated with both Spanish-speaking ability and cultural competency both of which are associated with greater patient satisfaction. Schnecker et al. conducted a cross-sectional study and found that discordant patients were more likely than concordant patients to report suboptimal interactions in physician not understanding, lack of confidence/trust, physician not showing respect and patient being treated poorly because of language (2010). Suboptimal interaction reports did not differ substantially between LEP-concordant and English-proficient patients. 


\section{Improved Health Outcomes}

Physician language concordance improved communication to the patient. Fernandez et al. surveyed 116 Spanish-speaking patients with diabetes, and 48 primary care physicians at a public hospital with translator's services (2004). They found that physicians fluent in Spanish were more likely than their non-fluent colleagues to evoke their patients' problems and concerns. Language concordant physicians were more likely to communicate longer to patients and less likely to ignore patient questions as compared to physicians using an translator. Physicians communicating via a translator made fewer facilitative remarks to their patient during encounters and subsequently patients were less likely to ask questions. Physician language concordance not only mitigated the issue of communication but also allowed patients to feel comfortable enough to discuss their confusion with medications and self-care (Street et al., 2008). In order to obtain these benefits, Wilson et al. found that Latino patients with LEP will travel long distances in order to consult a language-concordant physician (2005).

Physician language concordance improved health outcomes for patients with limited English proficiency as compared to patients provided with a translator. Stronger patientphysician communication is known to lead to improved health outcomes as patients feel comfortable asking questions and managing their own care. In clinical settings, patient centered communication styles have been associated with improved outcomes for diseases such as Diabetes (Fernandez et al., 2004). In a 2011 cross-sectional, observational study by Fernandez et al., patients with physician language concordance had better diabetes outcomes than patients with a non-concordant physician (Fernandez et al., 2011). The study also found that LEP was an independent predictor for poor glycemic control among Latino diabetic patients, however this association was not observed when patients were seen by language-concordant physicians. 
Ultimately, patients received more accurate and improved healthcare when provided for by a language-concordant physician, while patients receiving care from a non-language concordant physicians experienced inferior health outcomes. It should be noted that while physician language concordance increases medical comprehension and lowers risk of adverse reactions to misuse of medications in Latino patients, it may not address additional language-related barriers believed to caused by limited functional health literacy (Schillinger et al., 2004, Wilson et al., 2005). Physician language concordance mitigates complication associated with language barriers, however the complicated healthcare system and lack of health literacy for patients continue to make medical comprehension and self-care difficult.

\section{CONCLUSIONS}

Limited English Proficiency in adults poses a difficult burden upon the children of Spanish-speaking only parents. Due to the lack of access to professional translators especially in primary care settings, children are often used as translators despite potentially associated poor health outcomes and ethical concerns about children taking on this responsibility. Parental dependence, which causes stress on the child, goes beyond children managing patient appointments and involved translating the medical system for their parents. This dependence on children to interpret the medical field forces them to perform beyond their capabilities e.g. interpreting dosage and legal documents. While children may have the bilingualism to make them qualified to translate, depending on development the child may lack the knowledge and vocabulary to effectively communicate with a provider. Lastly, there is a fear that patients will withhold medical history and information to a provider when their child is in the appointment translating. 
The research showed that health outcomes are better off for Latino patients with language concordant providers due to improved communication. However, when Latino patients are provided for by a language disconcordant physician, health outcomes decrease. Discharge instructions and at home self-care are often not communicated effectively to patients with limited English proficiency. Many patients with LEP leave appointments without being able to have asked questions and feeling unable to properly follow self-care instructions, however this could be mediated by language concordant physicians. When patients have access to physician language concordance they are able to ask questions more freely and physicians spent more time clarifying during appointments. One of the most crucial findings was that concordant physicians were more likely to evoke questions and concerns in LEP patients. The communication between patient and provider is important for stimulating dialogue about self-care and treatment. This is significant when determining diabetes interventions, a health disparity with high prevalence in the Latino community. Diabetes management for Latinos with LEP could be improved when patients are effectively communicated via language concordance. Although language concordance improves health outcomes, the research showed that health literacy plays an important and separate role in understanding patient-physician communication in regards to health outcomes. Health literacy and limited English Proficiency, while associated, are separate indicators of health outcomes.

Research showed that translators decrease positive health outcomes as compared to physician concordance and children working as translators can be unethical and potentially ineffective. Understanding that children can make communication errors when stressed, hospitals should make a greater attempt to put LEP patients and their children at ease. Introducing a system for identifying these patients early on, possibly before the provider even reaches the 
patient, could help in providing appropriate communication resources to these patients. With the rise of electronic medical records, notes can be kept on a medical record and travel with the patient making them easily identifiable to providers. Many of the malpractice cases showed providers lack to identify patients with LEP and the patients subsequently experienced miscommunications in treatment leading to death and irreparable damage. Even in the events where identifications were made early on in the visit by nurses and providers, these notes were never documented in an electronic medical record. The significance of improved communication and health outcomes associated with physician language concordance could be beneficial in diabetes management. With diabetes being highly prevalent in the Latino community, public health officials should recognize the benefits and strengths of physician language concordance as a means of improved patient diabetes management.

The results showed that when Latinos with limited English proficiency encounter an English-only healthcare setting they are presented with the one of the following options for communication: concordant physicians, child translators, or a hospital employed translators. Preliminary research showed a significant body of research devoted to professional healthcare translators, however little research had been conducted regarding children as translators and physician language concordance despite hospitals and clinics recognizing that children often have to interpret for parents when there are no other options. Performing a review of the literature was an appropriate way to gauge how much research has been performed to evaluate the benefits of physician language concordance and the prevalence of children as translators. Despite the limited research in communication methods, the significant population of Latinos with LEP in the United States indicates this population must be receiving care in one of the three aforementioned means of communication. 
In order to further understand the impacts of professional and familial translators, it would be beneficial for further research to be conducted in order to examine LEP-patients provided for by translators in comparison to family translators, specifically children. It appears that hospitals are moving towards phone and in-person translators, when accessible, as concordant physicians are in low supply in certain areas of the United States. More research also needs to be conducted to evaluate the cost-benefit of minors translating, particularly to determine an appropriate age a child can act as a translator for a parent. Understanding that translators decrease the patient-provider relationship, steps must be made to improve this dynamic. The current model for professional medical translators is to have translators be "invisible" in order to maintain the patient-provider relationship. However, this model has not been effective and instead has made patients uncomfortable by the presence of an additional person. Modifying the current model and having translators have a more unifying presence could strengthen the patientphysician bond. 


\section{REFERENCES}

Alexandria, V. (2014, July 24). Diabetes Among Latinos: All Are Not Equal. Retrieved May 1, 2016, from http://www.diabetes.org/newsroom/press-releases/2014/diabetes-amongLatinos-all-are-not-equal.html?referrer=https://www.google.com/

Arriagada, P. (2005). Family Context and Spanish-Language Use: A Study of Latino Children in the United States. Social Science Quarterly (Wiley-Blackwell), 86(3), 599-619. doi:10.1111/j.0038-4941.2005.00320.x

Burgen, Stephen. (2015, June 29). US now has more Spanish speakers than Spain - only Mexico has more. Retrieved May 1, 2016, from http://www.theguardian.com/usnews/2015/jun/29/us-second-biggest-spanish-speaking-country

Centers for Disease Control and Prevention (CDC). (2015). Overweight \& Obesity: Childhood Obesity Facts. Retrieved from http://www.cdc.gov/obesity/data/childhood.html

Cohn, G. (2014, August 15). California Translator Bill Would Help Save Lives Lost in Translation. Retreived May 1, 2016, from http://www.huffingtonpost.com/2013/08/20/california-translator-bi_n_3785419.html

Powe, N., \& Cooper, L. (2004, July 1). Disparities in Patient Experiences, Health Care Processes, and Outcomes: The Role of Patient-Provider Racial, Ethnic, and Language Concordance. Retrieved May 1, 2016, from http://www.commonwealthfund.org/publications/fund-reports/2004/jul/disparities-inpatient-experiences--health-care-processes--and-outcomes--the-role-of-patient-provider

Foden-Vencil, K. (2014, October 27). In The Hospital, A bad Translation Can Destroy a Life. Retrieved May 1, 2016, from http://www.npr.org/sections/healthshots/2014/10/27/358055673/in-the-hospital-a-bad-translation-can-destroy-a-lifenpr

Fernandez, A., Schillinger, D., Grumbach, K., Rosenthal, A., Stewart, A. L., Wang, F., \& PerezStable, E. J. (2004). Physician Language Ability and Cultural Competence An Exploratory Study of Communication with Spanish-speaking Patients. JGIM: Journal Of General Internal Medicine, 19(2), 167-174. doi:10.1111/j.1525-1497.2004.30266.x

Fernandez, A., Schillinger, D., Warton, E., Alder, N., Moffet, H., Schnecker, Y., Salgado, M., Ahmed, A., \& Karter, A. (2011). Language barriers, physician-patient language concordance, and glycemic control among insured Latinos with diabetes: the Diabetes Study of Northern California (DISTANCE). JGIM: Journal Of General Internal Medicine, 26(2), 170-176. doi: 10.1007/s11606-010-1507-6

Jauregui, A. (2006, May 19). Kids Interpreting Medical Information to Parents. Retrieved May 1, 2016, from http://www.npr.org/templates/story/story.php?storyId=5418069

Ogden, C., Carroll, M., Kit, B., \& Flegal, K. (2012). Prevalence of obesity among adults: United States, 2011-2012. NCHS data brief, no. 131. Hyattsville, MD: National Center for Health Statistics, 2013. 
Orellana, M., Dorner, L., \& Pulido, L. (2003). Accessing Assets: Immigrant Youth's Work as Family Translators or "Para-Phrasers". Social Problems, 50(4), 505-524.

Pérez-Escamilla, R. (2010). Health Care Access Among Latinos: Implications for Social and Health Care Reforms. Journal Of Latino Higher Education, 9(1), 43-60. doi:10.1177/1538192709349917

Quan, K. \& Lynch, J. (2010). The High Costs of Language Barriers in Medical Malpractice. National Health Law Program, 1-24.

Ryan, C. (2013). Language Use in the United States: 2011. Retrieved from http://www.census.gov/content/dam/Census/library/publications/2013/acs/acs-22.pdf

Schillinger, D., Bindman, A., Wang, F., Stewart, A. \& Piette, J. (2004). Functional health literacy and the quality of physician-patient communication among diabetes patients. Patient Education and Counseling, 52, 315-323. doi:10.1016/S07383991(03)00107-1

Schnecker, Y., Karter, A. , Schillinger, D., Warton, E., Alder, N., Moffet, H., Ahmed, A., \& Fernandez, A. (2010). The impact of limited English proficiency and physician language concordance on reports of clinical interactions among patients with diabetes: the DISTANCE study. Patient Education and Counseling, 81(2), 222-228. doi: 10.1016/j.pec.2010.02.005.

U.S. Census Bureau News. (2014). Hispanic Heritage Month 2014: Sept. 15- Oct. 15. Retrieved from http://www.census.gov/content/dam/Census/newsroom/facts-forfeatures/2014/cb14ff-22_hispanic.pdf

Tran, V. C. (2010). English Gain vs. Spanish Loss? Language Assimilation among SecondGeneration Latinos in Young Adulthood. Social Forces, 89(1), 257-284. 